
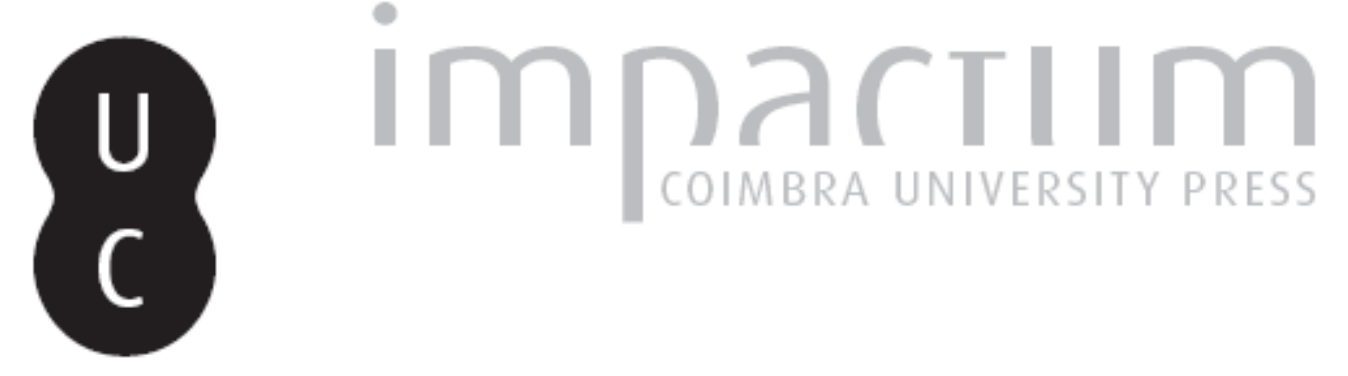

\title{
Regeneración de la vegetación y riesgos de erosion pos incendios forestales: estudio de casos en paises mediterraneos
}

Autor(es): $\quad$ Quintanilla P, Víctor; Lourenço, Luciano; Henriques, Susete

Publicado por: Associação Portuguesa de Riscos, Prevenção e Segurança

URL

persistente:

URI:http://hdl.handle.net/10316.2/35944

DOI:

DOI:http://dx.doi.org/10.14195/1647-7723_19_13

Accessed : $\quad$ 26-Apr-2023 16:18:43

A navegação consulta e descarregamento dos títulos inseridos nas Bibliotecas Digitais UC Digitalis, UC Pombalina e UC Impactum, pressupõem a aceitação plena e sem reservas dos Termos e Condições de Uso destas Bibliotecas Digitais, disponíveis em https://digitalis.uc.pt/pt-pt/termos.

Conforme exposto nos referidos Termos e Condições de Uso, o descarregamento de títulos de acesso restrito requer uma licença válida de autorização devendo o utilizador aceder ao(s) documento(s) a partir de um endereço de IP da instituição detentora da supramencionada licença.

Ao utilizador é apenas permitido o descarregamento para uso pessoal, pelo que o emprego do(s) título(s) descarregado(s) para outro fim, designadamente comercial, carece de autorização do respetivo autor ou editor da obra.

Na medida em que todas as obras da UC Digitalis se encontram protegidas pelo Código do Direito de Autor e Direitos Conexos e demais legislação aplicável, toda a cópia, parcial ou total, deste documento, nos casos em que é legalmente admitida, deverá conter ou fazer-se acompanhar por este aviso.

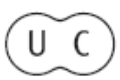




\section{territorium}

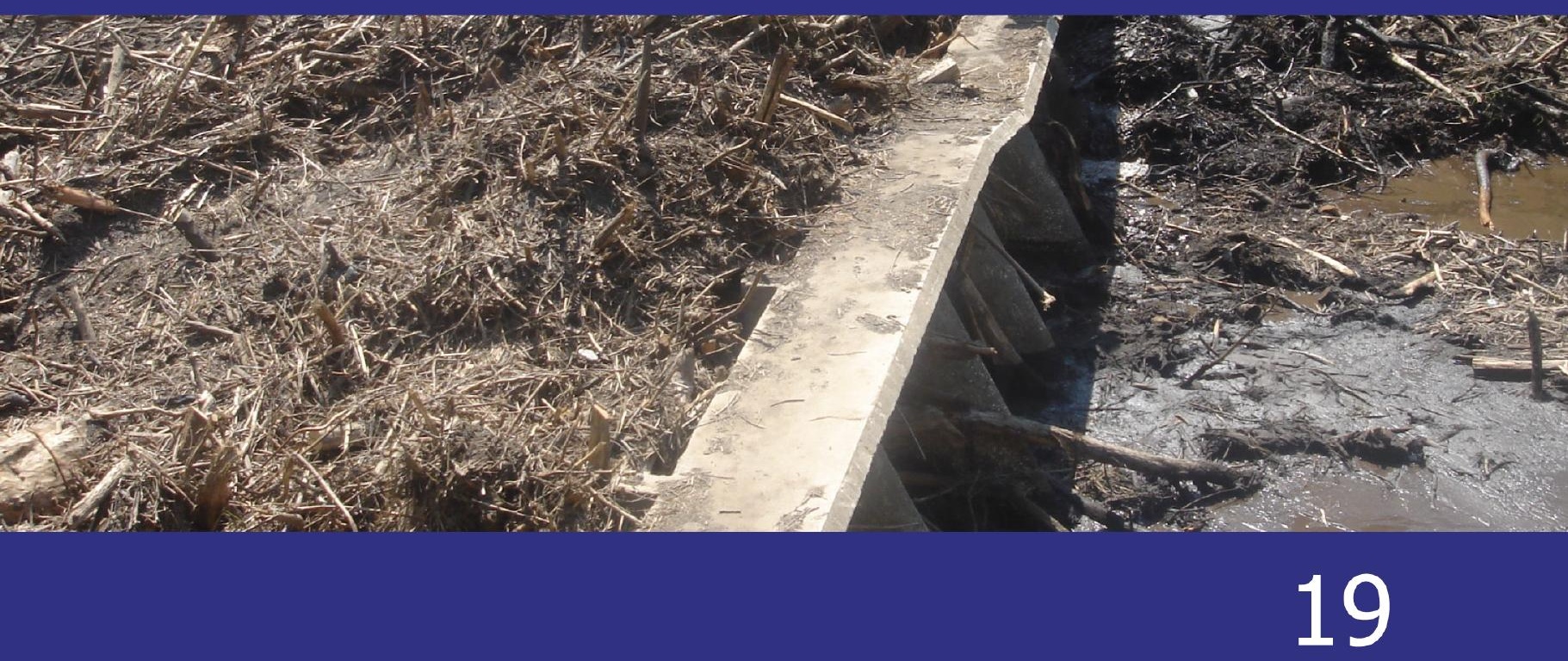

\section{Reequacionar o Conhecimento dos Riscos e das Catástrofes}

Revista da Associação Portuguesa de Riscos, Prevenção e Segurança 


\section{ESTUDIO DE CASOS EN PAISES MEDITERRANEOS*}

Víctor Quintanilla P

Universidad de Santiago de Chile vquintan@usach.cl

Luciano Lourenço

Departamento de Geografía; Universidad de Coímbra. Portugal luciano@uc.pt

Susete Henriques suseteanjos@hotmail.com

\section{RESUMEN}

Se presentan tipos de efectos erosivos por fuegos vegetales, acaecidos en sectores de la zona mediterránea de Chile y Portugal. La zona mediterránea de Chile es donde anualmente se desarrolla la mayor parte de los incendios forestales de verano, en una región comprendida aproximadamente entre los $32^{\circ}$ y $36^{\circ}$ latitud sur. En Portugal, es la región Centro, ubicada entre los $39^{\circ}$ y $41^{\circ}$ latitud norte, la que detiene más superficie quemada por incendios forestales y la que suele registrar los incendios más grandes.

Palabras clave: Incendios forestales, quema de vegetación, erosión, rebrote, regeneración.

RESUMO

Regeneração da vegetação e risco de erosão após incêndios florestais. Estudo de casos em países mediterrâneos - Apresentam-se alguns tipos de efeitos erosivos devidos a incêndios florestais ocorridos em áreas das regiões mediterrâneas do Chile e de Portugal. A zona mediterrânea de Chile é onde anualmente se desenvolve a maioria dos incêndios florestais de verão, numa região situada entre cerca de $32^{\circ}$ e $36^{\circ}$ de latitude sul. Em Portugal é a região centro, situada entre $39^{\circ}$ e $41^{\circ}$ de latitude norte, aquela que costuma ter a maior área anualmente queimada pelos incêndios florestais e é também a que regista os maiores incêndios.

Palavras chave: Incêndios florestais, queima de vegetação, erosão, rebentação, regeneração.

\section{RÉSUMÉ}

Régénération de la végétation et le risque d'érosion après les feux de forêt. Étude de cas dans les pays méditerranéens - Sont présentés quelques types d'effets érosifs dus aux feux de forêt, dans certaines zones de la région méditerranéenne du Chili et du Portugal. La zone méditerranéenne du Chili est l'endroit où, chaque année, se développe plus de feux de forêt d'été dans une région située entre environ $32^{\circ}$ et $36^{\circ}$ de latitude sud. Au Portugal, est dans la région centrale, située entre $39^{\circ}$ et $41^{\circ}$ de latitude nord, celle qui a généralement la plus grande surface brûlée par les feux de forêt et note également des plus grands incendies.

Mots clés: Feux de forêts, brûlage de la végétation, l'érosion, la repousse et la régénération.

\section{ABSTRACT}

Regeneration of vegetation and erosion risk after forest fires. Case study in Mediterranean countries - We present some types of erosive effects due to forest fires in areas of the Mediterranean regions of Chile and Portugal. The Mediterranean zone of Chile is where annually develops most of summer wildfires in a region between about $32^{\circ}$ and $36^{\circ}$ south latitude. Portugal is in the central region, located between $39^{\circ}$ and $41^{\circ}$ north latitude, that accustom to having the largest area burned annually by wildfires and also notes that the largest fires.

Key words: Wildfires, burning of vegetation, erosion, renewal, regeneration.

\footnotetext{
* O texto deste artigo foi submetido para revisão em 16-09-2011, tendo sido aceite para publicação em 13-12-2011. Este artigo é parte integrante da Revista Territorium, $n .019,2012,{ }^{\circ}$ RIscos, ISBN: 0872- 8941.
} 


\section{Introdução}

El fuego se ha vuelto un problema de conservación, esto porque muchas áreas en todo el mundo dependen de éste para mantener tanto sus especies como hábitats y paisajes nativos, siendo ecosistemas dependientes del fuego. En contraste, hay otras áreas en las que el fuego puede llevar a la destrucción o pérdida de especies y de hábitats naturales; estas áreas se conocen como ecosistemas sensibles al fuego, y que además, son frecuentes en las regiones mediterráneas.

Los incendios forestales, además de consumir la vegetación, y a veces, el patrimonio edificado, frecuentemente desencadenan efectos subsecuentes, que entre otros, se traducen en el aumento del riesgo de erosión hídrica del suelo (L. Lourenço et al. 1991), llegando al punto de poner en peligro la estabilidad de las vertientes (L. Lourenço, 1988). Los grandes episodios de fuegos agravan los efectos de pérdida del suelo, sobre todo en áreas donde la vegetación es menos abundante y donde es más difícil conservarla. Como resultado, muchas áreas de colinas que antes de los incendios presentaban suelos delgados, quedan reducidos posteriormente a suelos esqueléticos, o incluso pueden verse completamente desprovistos de cualquier tipo de suelo, aflorando la roca desnuda en la superficie. Ante estas condiciones, las especies más robustas consiguen regenerarse, pero el ordenamiento forestal queda muy comprometido y fuertemente condicionado a la introducción de especies más exigentes desde el punto de vista del suelo, como es el caso de las especies latifoliadas, que en ciertos sitios generalmente no era posible su desarrollo (L. Lourenco, 2004).

Los servicios provistos por los ecosistemas tales como el aire limpio, agua limpia y suelos saludables y productivos, pueden verse afectados por el fuego de modo negativo o positivo, dependiendo de las adaptaciones de las especies y de otras características del medio ambiente, y de cuan frecuente e intensa sea la quema del área. La erosión es regularmente un fenómeno subyacente en las áreas incendiadas, particularmente si ocurren en terrenos de pendientes.

\section{Material y metodos}

Para el tema relacionado con los casos de estudios en Chile mediterráneo, el trabajo de gabinete se centró fundamentalmente en la interpretación de fotografías aéreas, análisis de cartas topográficas y temáticas, revisión bibliográfica y análisis de imágenes satelitales Landsat (TM-ETM+). El trabajo de campo fue el apoyo principal para el estudio, donde además de las observaciones de terreno, se llevaron a cabo censos vegetales y seguimiento de procesos erosivos.
De igual modo, la metodologia seguida en Portugal fue semejante. Además de la consulta de las fuentes documentales, el trabajo de campo que fue la principal fuente de información, tanto para estudiar la evolución de la vegetación después de los incendios, como para acompañar los efectos erosivos en secuencia de la precipitación normal bien como después de precipitaciones intensas, en distintos materiales rocosos (L. Lourenço et al., 1991).

\section{Casos en Chile}

Estos países en su zona mediterránea poseen importantes superficies de territorios propensos al fuego, afectando tanto los bosques nativos como de especies exóticas. Los fuegos han ido aumentando como consecuencia principal de los cambios del uso del suelo; por ejemplo el abandono de prácticas tradicionales agrícola y de pastoreo, está generando combustibles en un contexto paisajístico nuevo, donde quizás nunca antes había existido (VÉLEZ, 2005).

En Chile central o mediterráneo, los procesos de erosión tienen una especial importancia, porque se trata de espacios de colinas y montañas, que están caracterizados por fuertes pendientes y predominancia de suelos graníticos, preferentemente arcillosos (ScHLATTER et al., 2003); y porque también está concentrada gran parte de la población a nivel nacional, por lo que el uso intensivo de las tierras se realiza hace bastante tiempo. Además estas áreas presentan lluvias que pueden tener un alto poder abrasivo, desencadenando potencialmente procesos erosivos de gran intensidad (Fuentes et al., 1998).

Como consecuencia de lo abrasivo que pueda resultar el clima, lo accidentado del relieve, y la relativa escasez de terrenos planos; se favorece la gran extracción y transporte masivo de materiales hacia el mar. Los tipos de incendios de suelo en montaña, precisamente contribuyen a la desagregación de las partículas del sustrato contribuyendo al proceso de erosión.

En Chile mediterráneo se localizan las regiones administrativas ( $\mathrm{V}$ - VI región) que alcanzan el mayor número de fuegos en el año en todo el país (fig. 1). En la temporada del año 2009 hubo alrededor de 1.750 focos de incendios. Cabe señalar que esta área de Chile central, 50 años atrás aproximadamente, poseía en gran parte de su territorio, un denso bosque esclerófilo. Sin embargo en la actualidad este bosque en ciertos sectores se ha quemado regularmente cada año (QuINTANILLA, 1988); en estos casos la erosión ya está en un notorio estado de avance (Quintanilla \& CAstillo, 2009) (fig. 2).

En el valle central de Chile, a raíz de los incendios, se han ido paulatinamente produciendo modificaciones del paisaje; las planicies cubiertas en el pasado con el 


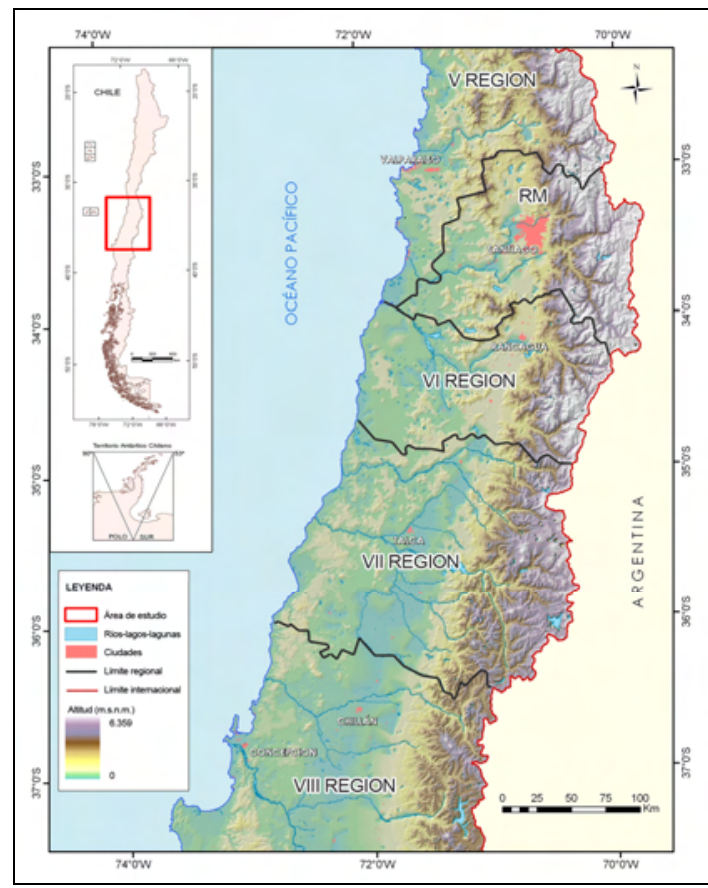

Fig. 1 - Región mediterránea de Chile.

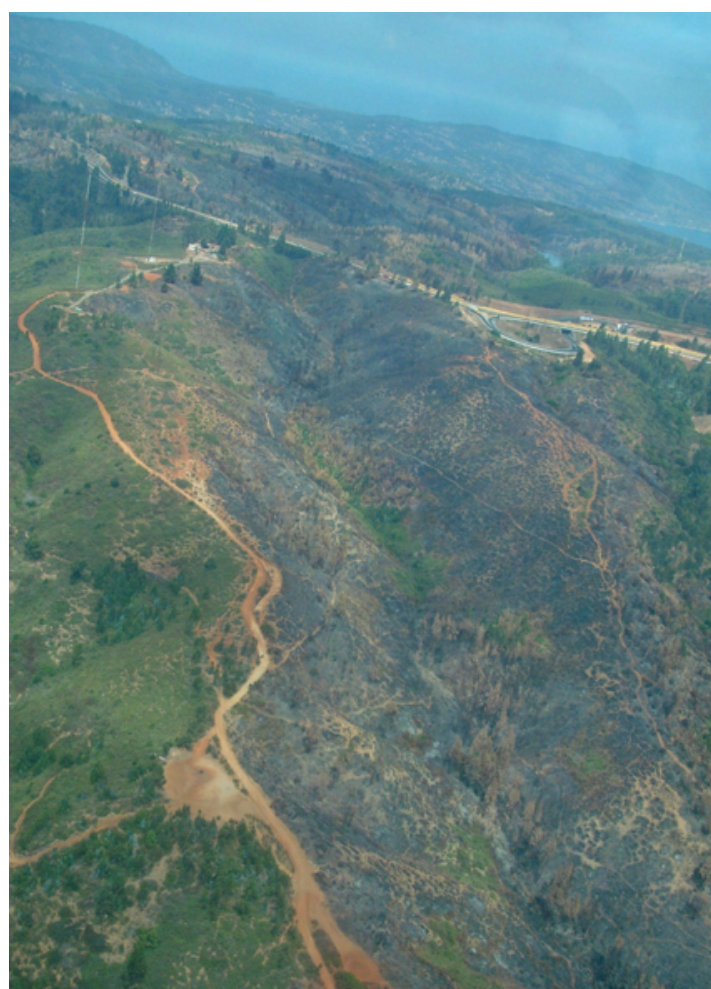

Fig. 2 - Grandes extensiones de bosque afectadas por los fuegos, con efectos erosivos post-incendios.

"espinal" de Acacia caven, actualmente se encuentran bastante dispersas, provocando un gran retroceso de bosque de Lithraea caustica-Quillaja saponaria quedando hoy en día fragmentos de esta agrupación (GUERRA, 2002).
En un palmar de Jubaea chilensis localizado aproximadamente en los $33^{\circ}$ de latitud sur, existen testimonios de un gran fuego en ladera de solana, donde se ha quemado el matorral esclerófilo que acompaña a la palma. Este sector, entre 1998 y el 2007, ha sido afectado 4 veces por los fuegos. En consecuencia, no solo la regeneración se ha resentido anualmente sino también la capa vegetal del suelo habría disminuido entre 6 y $8 \mathrm{~cm}$ en ese periodo (fig. 3).

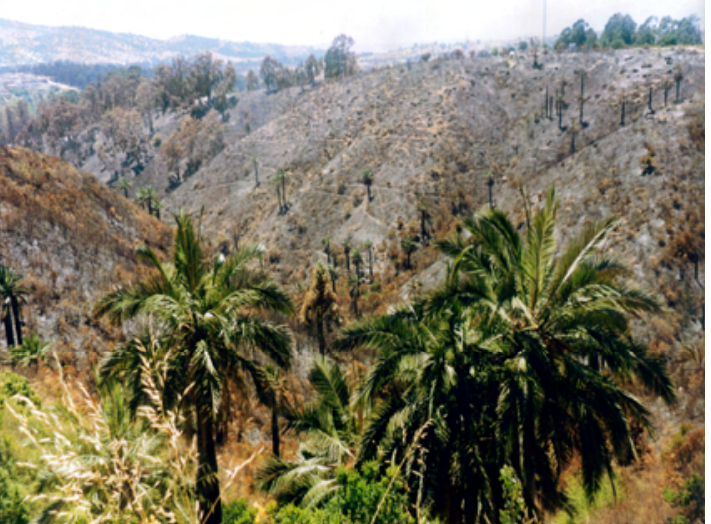

Fig. 3 - Fuegos en colinas de J ubaea chilensis durante el 2007 y que han desencadenado procesos erosivos.

Por otra parte, en la actualidad se detectan fenómenos de erosión en surco en las pendientes. El efecto del fuego determina la pérdida de la cubierta vegetal, generando en los suelos una mayor susceptibilidad de ser erosionados por la acción de las lluvias y el viento, arrastrando de este modo sus capas superficiales. Este arrastre implica además la pérdida de las semillas del suelo, lo que se traduce en el retardo de la eventual regeneración del paisaje (AvILA et al., 1998).

Alrededor de los $34^{\circ}$ de latitud sur de la cordillera costera, se han producido (enero del 2009) fuegos del matorral esclerófilo, afectando algunos árboles nativos como Lithraea caustica, Quillaja saponaria y Kageneckia oblonga. En pendientes de unos $45^{\circ}$ el fuego arrasó con todo el manto vegetal, tras lo cual durante las Iluvias de invierno, no sólo hubo erosión hídrica sino también se desencadenaron desprendimientos y rodados en laderas. La regeneración del año siguiente aún no ha hecho posible que se inicie el restablecimiento de la fisionomía anterior del paisaje (Fig. 4 y 5).

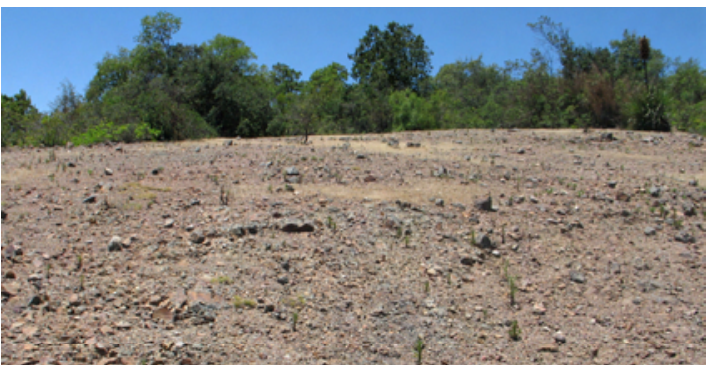

Fig. 4 - En una meseta de alta montaña después de reiterados fuegos, queda el desnudo y el suelo pedregoso. 


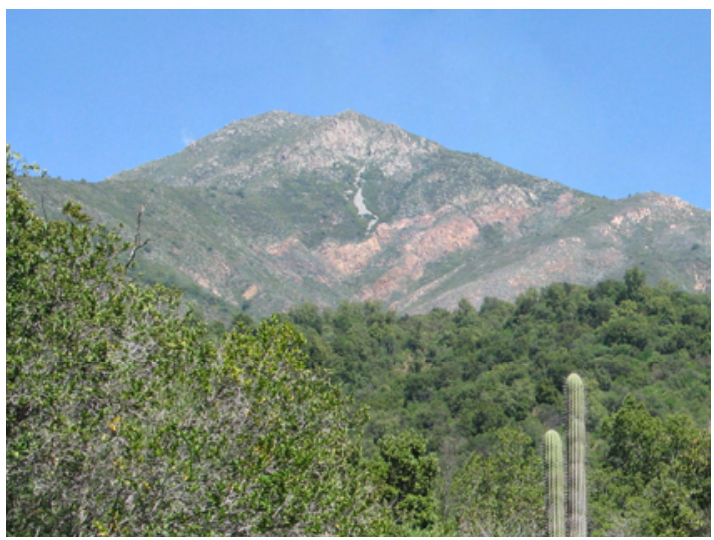

Fig. 5 - Cordón montañoso Altos de Cantillana con evidencias de incendios y de procesos erosivos y de remoción en masa.

Los fenómenos de cárcavas son frecuentes en aquellos lugares donde, antes, hubo bosque esclerófilo. No obstante la regeneración de la vegetación post-fuego, bajo la fisionomía de matorral esclerófilo abierto, en la parte superior de las colinas, el suelo ha tenido una fuerte erosión (fig. 6), sobre todo donde hay pastoreo.

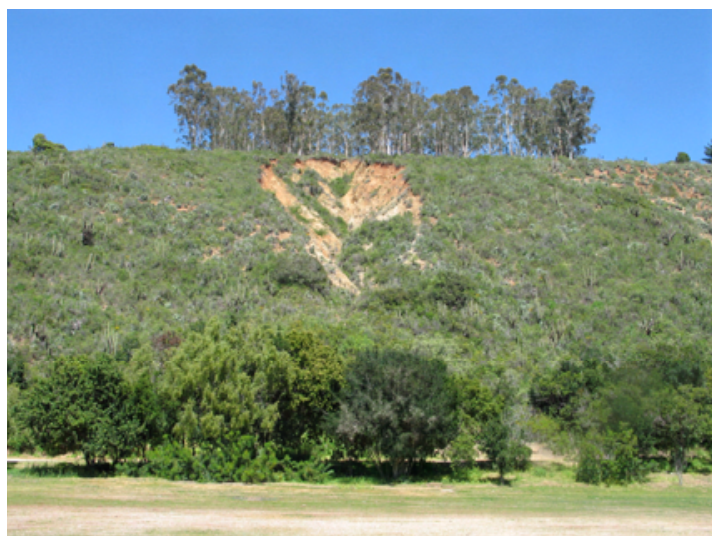

Fig. 6 - Matorral post-fuego con procesos de erosión avanzado (cárcavas).

Particularmente los fuegos en los bosques de Nothofagus (robles) acaecidos en el piso altomontano de la cordillera costera, han generado en suelos rocosos y laderas de fuertes pendientes una erosión avanzada, y también procesos de remoción en masa (rodados) al perder la cubierta arbórea en esos terrenos.

La baja infiltración de los suelos en Chile mediterráneo contribuye a un alto escurrimiento. La erosión de manto ha conducido a la pérdida de la capa superficial del suelo y la erosión linear va provocando un arroyamiento, sobre todo en las laderas más quemadas, las cuales a menudo se encuentran en exposición norte (ENDLICHER, 1988).

El verano de Chile central se caracteriza por presentar períodos secos, fuerte insolación, alta temperatura atmosférica y del suelo, escasa humedad y vientos de alta velocidad. Durante el periodo estival pueden contarse 7 a 8 períodos secos por lo menos, y no más de 5 días con precipitación. La sequía de verano produce la resecación de la superficie del suelo, la formación de fisuras en el perfil del suelo y la desintegración mecánica del sustrato granítico (QuinTANiLla, 1987).

Cuando se queman las agrupaciones del matorral esclerófilo abierto, particularmente en los fuegos de suelo y subsuelo en fuertes pendientes, dejan expuesto el sustrato a la erosión. No se produce una infiltración rápida de las lluvias, por lo que los agregados quedan sueltos; y en el intertanto en que se regenera la vegetación herbácea y arbustiva post-fuego (después de 6 a 8 meses), al menos se desencadena una erosión laminar.

De acuerdo al valor geobotánico de las áreas afectadas por sucesivos o grandes incendios, se quiere poner énfasis en las características de 3 o 4 tipos de ambientes ecológicos.

Uno de estos corresponde al bosque y al matorral esclerófilo del centro de Chile mediterráneo. El matorral actualmente corresponde a una forma de retroceso y degradación del bosque primitivo esclerófilo. Al tener escasa cobertura, el acceso de los incendios es rápido, los fuegos son muy continuos y las laderas que se queman, con pobre regeneración, se erosionan pronto. Actualmente el bosque esclerófilo, en la mayoría de los casos, corresponde a agrupaciones en fase de regeneración post-fuego afectadas por pastoreo, por lo cual los fenómenos erosivos no están ausentes (fig. 7 y 8 ).

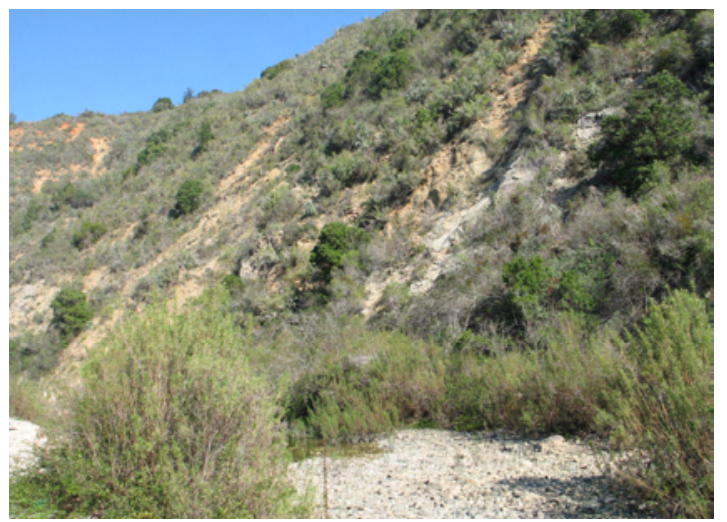

Fig. 7 - Matorral esclerófilo distribuido en un sector de altas pendientes.

Mención aparte merecen los relictos de palmeras de Jubaea chilensis Baillon, la palma más austral del mundo, que preferentemente forma bosques en enclaves de colinas. Uno de estos escasos bosques está situado en el cordón costero que bordea a las ciudades de Valparaíso y Viña del Mar.

La presión demográfica de estas ciudades ha generado en el litoral el origen de numerosos fuegos en los últimos 15 años, sobre todo en los bosques de palmas. Estos árboles centenarios que resisten considerablemente al fuego, al 


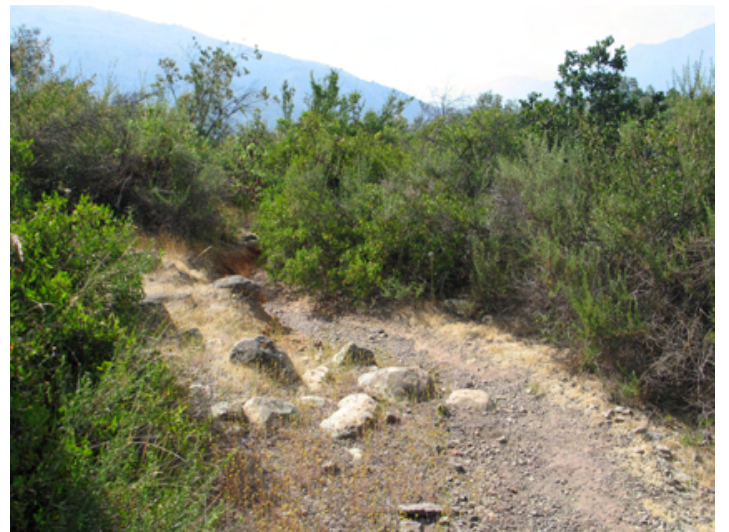

Fig. 8 - Matorral esclerófilo terrenos erosionados después de los fuegos.

situarse la mayoría de los individuos en superficies de pendientes; su sustrato es afectado por fenómenos de erosión con bastante recurrencia (QUINTANILLA 2009) (fig. 9 y 10).

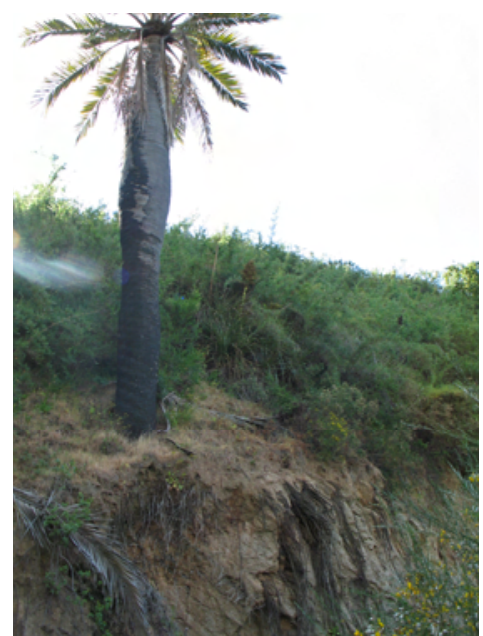

Fig. 9 - Erosión post-fuegos en laderas quemadas de la palma J ubaea chilensis.
También en la cordillera costera los fuegos vegetales han tenido una recurrencia frecuente, especialmente en los sectores de suelos rojos arcillosos, donde la vegetación que sustentan se quema en gran parte, y en particular, en aquellas laderas de exposición en solana. En los sectores quemados con pendientes superiores a $35^{\circ}$, y con perdida de toda la cubierta vegetal; en el invierno siguiente las precipitaciones suelen dar origen a deslizamientos (fig. 11).

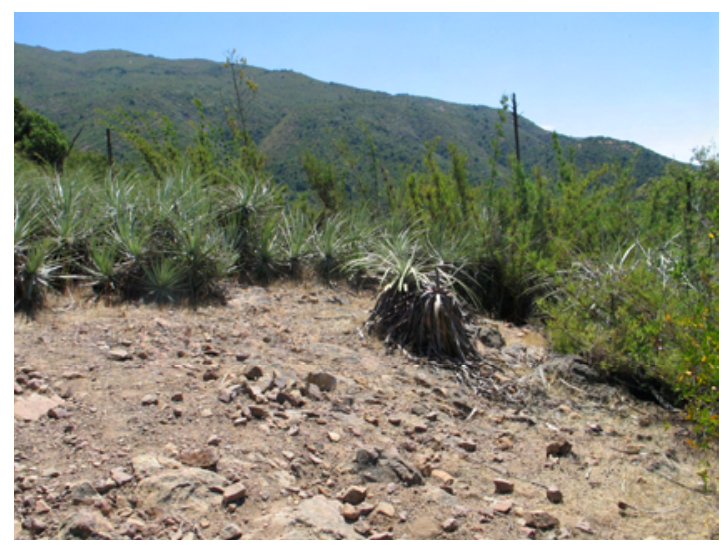

Fig. 11 - Montaña erosionada post-fuego y con regeneración de especies xéricas.

En las cumbres más altas de la cordillera costera mediterránea (1.800-2.200 m.s.n.m.) existe una vegetación de alto valor geobotánico. Aquí se desarrollan bosques de Nothofagus obliqua var. macrocarpa (roble de Santiago), el cual posee una distribución restringida en Chile, localizándose en laderas de exposición norte y este, en sectores frescos y húmedos. Desde 1987 estas agrupaciones han recibido impactos del fuego durante los últimos seis veranos.

Las laderas con exposición a barlovento, y de pendientes superiores a los $40^{\circ}$, sufrieron mayormente los efectos de

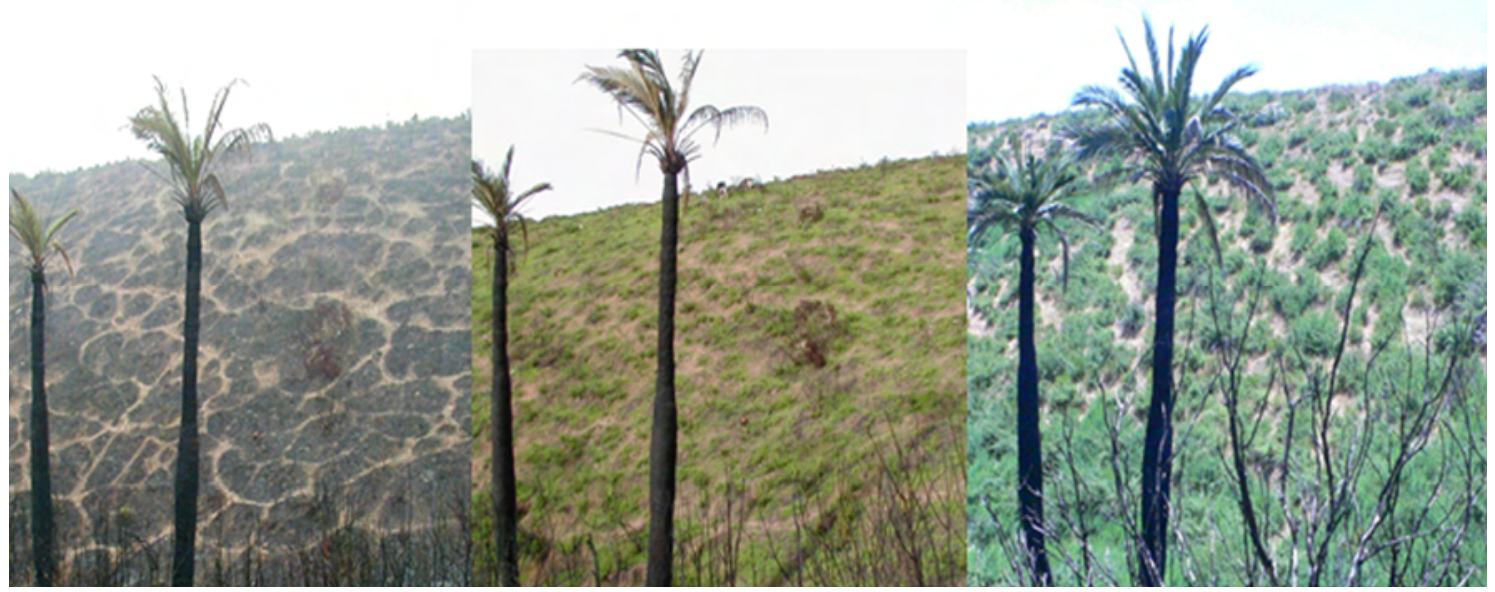

Fig. 10 - Situación de una ladera con palma chilena (J ubaea chilensis) con erosión en pendientes y con cobertura vegetal post-fuego de regeneración a lo largo de un año. 
los fuegos en octubre del año 2007, al punto de quedar los suelos sin bosque, teniendo como consecuencia que durante el invierno siguiente, se generaron procesos de deslizamientos y rodados. La erosión inclusive, bajo la cota de 1.500 metros de altitud, se presenta en estado de surcos.

\section{Casos en Portugal}

En Portugal, la Región Centro es la más afectada por los incendios forestales, no tanto por el numero, pués es la Región Norte la que detiene mayor promedio de ocorrencias, pero si por la importancia de las superficies quemedas, sobretodo en sus regiones más montañosas (fig. 12), que también suelen ser las más afectadas por la erosión después de incendios, que por ya se haber descrito en anteriores trabajos (L. Lourenço, 1988, 2004 y 2007) no se desarrolla aquí. En contrapartida se describe la evolución de la vegetación después de los incendios.

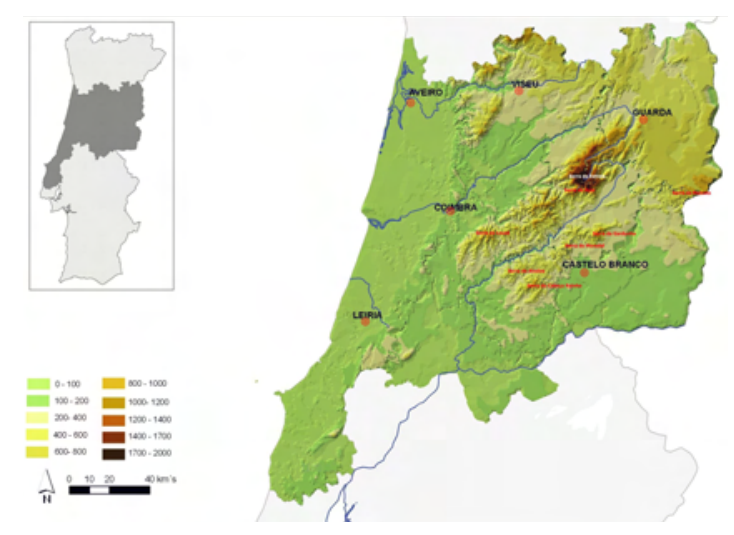

Fig. 12 - Hipsometria de la Région Centro de Portugal.

Los efectos de los incendios sobre la vegetación lleva a un cambio de los pinares tradicionales de Pinus pinaster por plantaciones de Eucalyptus globulus 0 , en las areas más montañosas, debido a incendios sucesivos, a la substitución del estrato arboreo por matorrales de cistaceas y ericaceas.

Despúes de los incendios, la vegatación va rebrotando. Primero, salen las herbaceas (fig. 13) y, más tarde, rebrota la vegetación nativa y alguna de la exotica, como los Eucalyptus y las Acacias, dealbata y melanoxylon, asunto que desarrollaremos.

Al nivel de cada planta, la consecuencia más drástica de un incendio consiste en su muerte, pero, normalmente, la mortalidad directamente provocada por el fuego alcanza apenas una pequeña parte de los individuos de cada comunidad vegetal (J. SILva, 2007).

Diferentes especies presentan diferentes tipos de sensibilidad al calor y son afectadas de modo diferente.
Las plantas de menor porte (herbáceas y arbustivas) suelen ser siempre las más afectadas, una vez que la mayor liberación de energía se verifica en los niveles próximos del suelo y, también, porque sus tallos son más delgados. Todavía, esto no significa que sean plantas a sufrir una mayor tasa de mortalidad, dada la capacidad que muchas poseen para lanzar nuevos rebrotes a partir de la base del tronco o de la raíz. Esta característica no está presente en algunas especies arbóreas, como, por ejemplo, en el pino (Pinus pinaster), como veremos más adelante. Todavía, los pinos son detentores de un tronco con cascara de espesor bastante elevado, lo que hace con que los tejidos vivos del tronco no sean tan afectados por las elevadas temperaturas resultantes del paso del fuego. De esta forma, la resistencia de un árbol al fuego depende mucho de la espesura y de la naturaleza de la cascara que tiene, así como de su estado de desarrollo. Los arboles más viejas, normalmente, son menos dañadas por el paso del fuego, debido al mayor espesor de la cascara y por la mayor altura de la base de la copa. Por el contrario, los arboles más jóvenes tienen mayor capacidad de recuperación relativamente a los daños sufridos por las llamas.

A partir de un estudio efectuado en seis áreas muestras de la Región Centro, entre septiembre de 2010 y julio de 2011, S. Henriques (2011), verificó que, después del incendio, la vegetación se regenera con relativa facilidad. Dos meses más tarde, a seguir a las primeras Iluvias, en octubre, el suelo empezó a quedar cubierto por los nuevos rebrotes vegetales o por la germinación de las semillas de algunas especies. En los meses de invierno la cobertura del suelo estaciona, sin desarrollarse, y solamente en la estación de primavera se nota un elevado aumento evolutivo. La área muestra más rellena fue la $B$, seguida por $E, A 1, D, A 2 y$, en último lugar, el área $C$, correspondiente a una área de pinar, donde la vegetación empezó a regenerarse y a desarrollarse apenas a partir del mes de febrero. La área B fue la única a relleñar la totalidad del espacio estudiado (1m2).

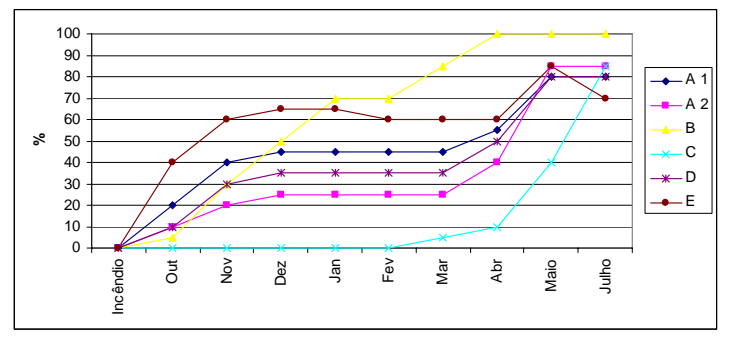

Fig. 13 - Evolución de la cobertura del suelo en las diversas áreas muestra estudiadas.

Las herbáceas fueron las primeras a regenerarse (fig. 14), siguiendo los arbustos, tales como, por ejemplo, la Festuca sp (fig. 15) y genistas: Cytisus multiflorus (fig. 16) y Cytisus striatus. Más tarde, los rebrotes de las 
frondosas empezaron a aparecer, como ha sucedido con los Quercus pyrenaica (fig. 17) y Fraxinus angustifolia (fig.18). Por fin, han surgido las resinosas, como el Pinus pinaster, que tardó más en regenerarse, una vez que este germina por medio de semilla (fig. 19).

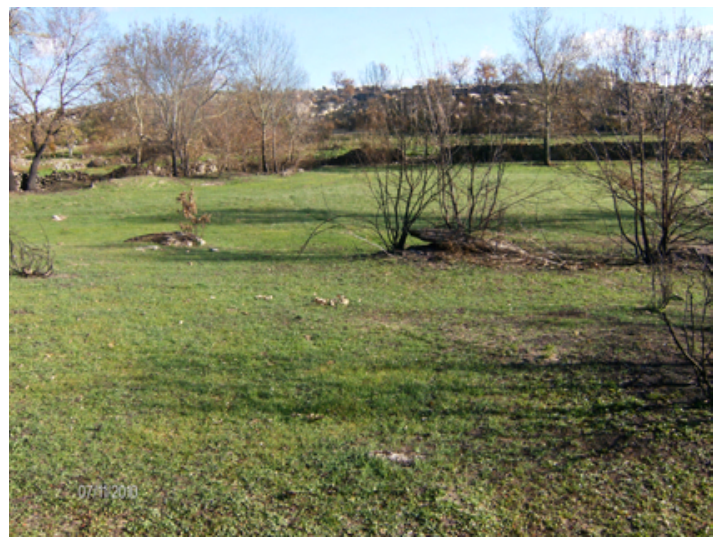

Fig. 14 - Regeneración de las herbáceas después del incendio forestal.

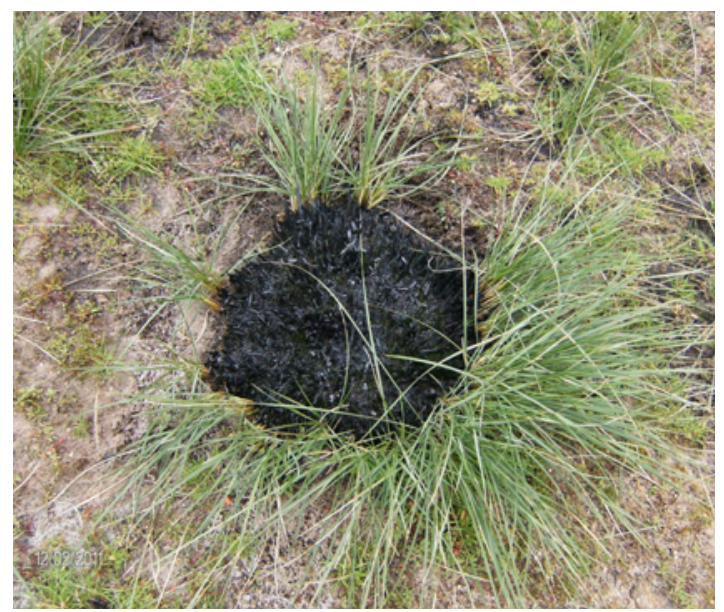

Fig. 15 - Regeneración de Festuca sp. seis meses después del incendio forestal.

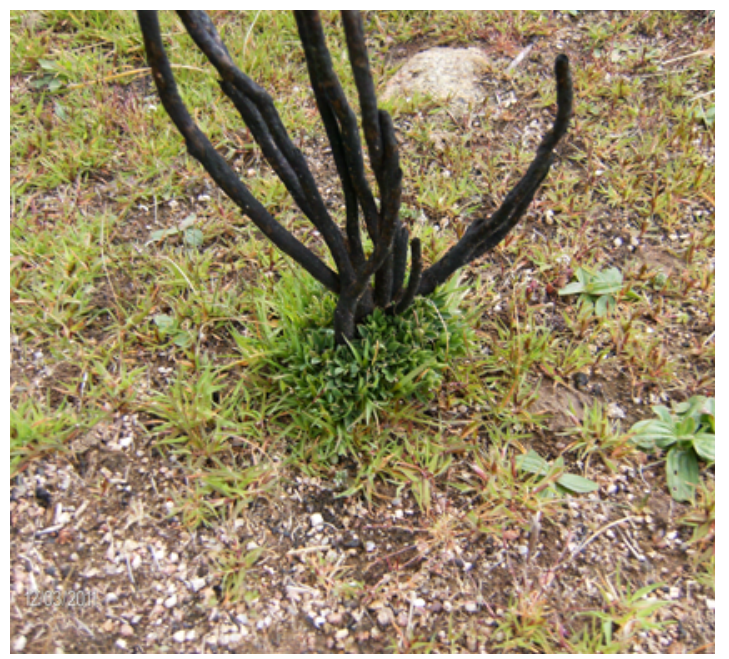

Fig. 16 - Regeneración de Cytisus multiflorus, siete meses después del incendio forestal.

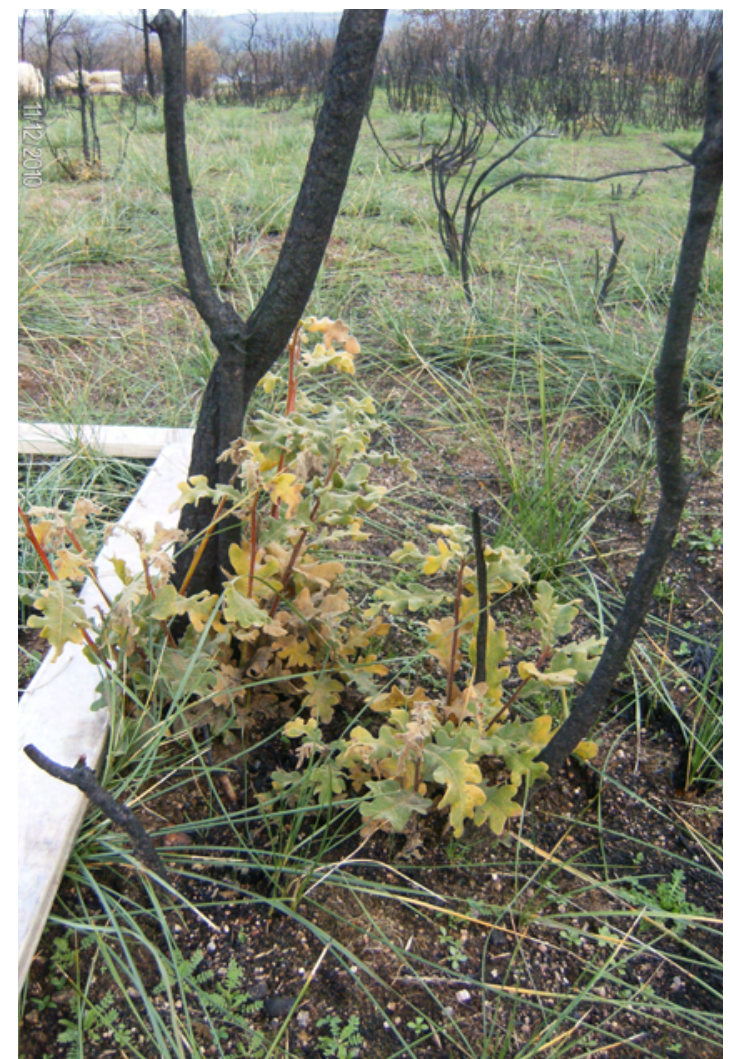

Fig. 17 - Regeneración de Quercus pyrenaica, cuatro meses después del incendio forestal.

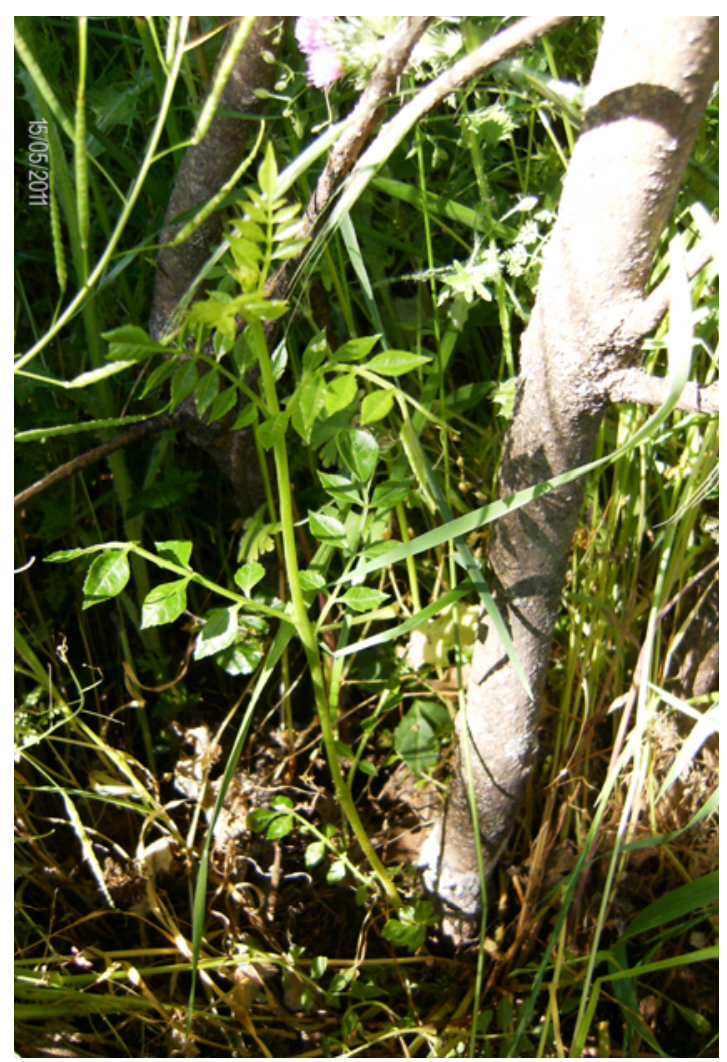

Fig. 18 - Regeneración de Fraxinus angustifolia, nueve meses después del incendio forestal. 


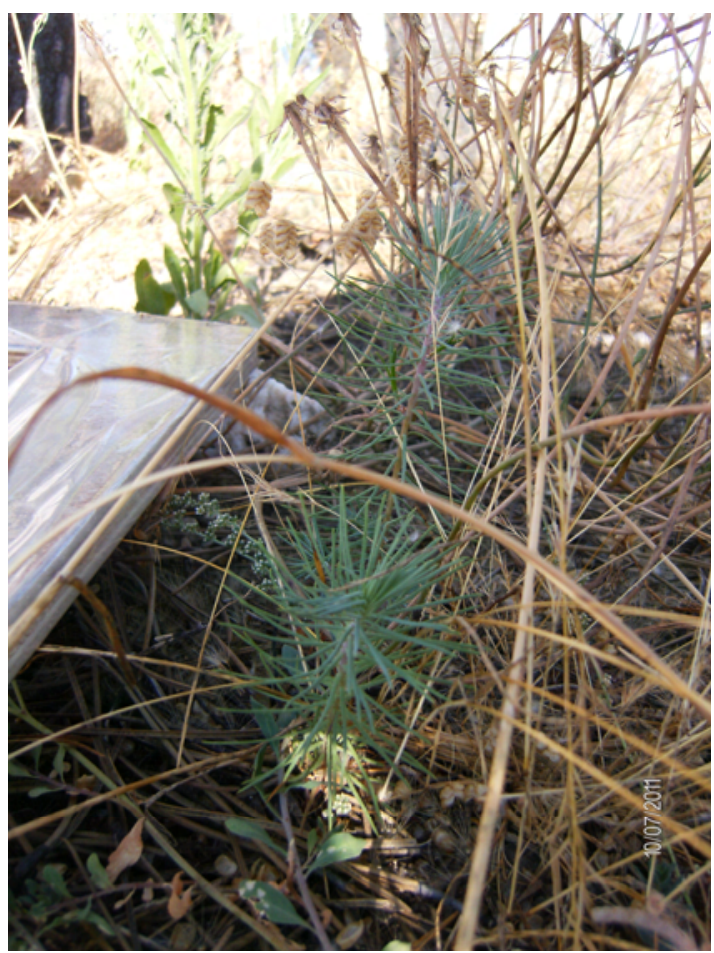

Fig. 19 - Nacimiento de Pinus pinaster, once meses después del incendio forestal.

\section{Conclusiones}

La erosión debida a los fuegos forestales es un fenómeno recurrente. En Chile mediterráneo, el largo y seco verano acompañado de fuertes vientos provenientes del suroeste, aceleran la erosión eólica, por lo cual se pierden muchas plántulas y semillas que posteriormente pueden iniciar la regeneración. En consecuencia la pérdida de cubierta vegetal contribuye a acelerar el desgaste del relieve. Esta situación es muy grave en la parte septentrional de Chile mediterráneo $\left(32^{\circ}-33^{\circ} \mathrm{S}\right)$, donde por la escasa presencia actual de agrupaciones leñosas y la frecuencia de incendios, algunas cuencas presentan fenómenos de desertificación. En Portugal, también ocurren situaciones de fuerte erosión, sobretodo donde las pendientes son más fuertes y cuando las lluvias de otoño e invierno son intensas, por ausencia de la vegetación.

\section{Referencias Bibliograficas}

Avila, G.; Aljaro, M.E. y Montenegro, G. (1988) - "Incendios en la vegetación mediterránea”. Ecología y Paisaje en Chile central. Universidad Católica de Chile, p. 81-87.

Endicher, W. (1988) - "El problema de la erosión del suelo en la cordillera de la costa”. Geografía Norte Grande, 15, Universidad Católica de Chile, p. 11-27.

Fuentes, E.; Espinoza, G. y Molina, J. (1988) - “La erosión fenómenos naturales y acción del hombre". Ecología del Paisaje de Chile Central. Universidad Católica de Chile, p. 53-64

Guerra, G. (2002) - "El fuego: sus daños y sus efectos". Agentes de daños al bosque nativo. Editorial Universitária. Santiago, p. 45.52

Henriques, S. (2011) - Reincidência de incêndios florestais no distrito da Guarda. Fatores desencadeantes e consequências ambientais da manifestação do risco dendrocaustológico. Dissertação de Mestrado em Geografia Física, Ambiente e Ordenamento do Território, apresentada à Fac. de Letras da Universidade de Coimbra.

Lourenço, L. (1988) - “Efeitos do temporal de 23 de Junho de 1988 na intensificação da erosão de vertentes afectadas pelo incêndio de Arganil/Oliveira do Hospital". Comunicações e Conclusões do Seminário Técnico sobre Parques e Conservação da Natureza nos Países do Sul da Europa, Faro, p. 43-77.

LouRenço, L. (2004) - Riscos de erosão após incêndios florestais. Coleção Estudos, 52. Universidade de Coimbra, $199 \mathrm{p}$.

Lourenço, L., (2007) - Riscos Ambientais e Formação de Professores (Atas das VI Jornadas Nacionais do Prosepe). Colectâneas Cindínicas VII, Projeto de Sensibilização e Educação Florestal e Núcleo de Investigação Científica de Incêndios Florestais e Faculdade de Letras da Universidade de Coimbra, Coimbra, 223 p.;

Lourenço, L.; Bento-Gonçalves, A. e Monteiro, R. (1991) - "Avaliação da erosão dos solos produzida na sequência de incêndios florestais". Comunicações do II Congresso Florestal Nacional, Porto, p. 834-844. 
Lourenço, L.; Rebelo, F.; Nave, A.; Pereira, N.; Silva, M.; Carvalho, A. e Fialho, J. (2006) - Paisagens de Socalcos e Riscos Naturais em vales do rio Alva. Colectâneas Cindínicas VI, Projeto Interreg III B/SUDOETERRISC, Núcleo de Investigação Científica de Incêndios Florestais da Faculdade de Letras da Universidade de Coimbra, Lousã, 192 p.

Mass, M. y J ARamillo, V. (2004) - Impactos de los incendios en el suelo. Depto. Incendios Forestales y Agrarios. UNAM. Méjico

Quintanilla, V. (1985) - "Carta Fitogeográfica de Chile mediterráneo". Rev.Contrib. Cint. Y Tec., $\mathrm{n}^{\circ}$ 70. Universidad de Santiago de Chile, Carta $y$ texto 33p.

Quintanilla, V. (1998) - “Los incendios de vegetación en el cordón costero de Chile central. El apoyo de la cartografía para su gestión y prevención". Rev. Contrb. Cient. y Tec, $\mathrm{n}^{\circ} 120$. Universidad de Santiago de Chile, 28 p. y carta color.
Quintanilla, V. y CAStillo, M. (2009) - “Degradación de ecosistemas de la palma más austral del mundo (Jubaea chilensis), acelerados por fuegos estivales en los cordones litorales de Valparaíso y Viña del Mar (32 ${ }^{\circ} 50-33^{\circ} 02$ S.)". Revista Investigaciones Geográficas, $n^{\circ} 412$. Universidad de Chile.

Schlatter, J .; R. Grez y Gerding, U. (2003) - Manual para el reconocimiento de suelos. Universidad Austral de Chile. 140 p.

SILVA, J. (2007) - "Proteger a floresta - Incêndios, pragas e doenças". Árvores e florestas de Portugal (Volume 8), Público, Comunicação Social S.A. e Fundação Luso-Americana para o Desenvolvimento, Lisboa.

VÉLEZ, Ricardo (2005). La población rural en la prevención de incendios forestales. FAO, Roma. 